\title{
Bioaccumulation of Chromium in Alternanthera philoxeroides Using Ion Microscopy (SIMS)
}

\author{
P.A.Mangabeira, * Alex-Alan F. de Almeida,* D.C. Silva,* A.H. Oliveira,* Valéria F. Fernandes, * \\ A.S. Ferreira*,A.J.dos Santos Júnior* P. Galle,* \\ * Centro de Microscopia Eletrônica, Departamento de Ciências Biológicas, Universidade Estadual \\ de Santa Cruz, Rodovia Ilhéus-Itabuna km 16, Ilhéus, Bahia 45662-900, Brazil.
}

The environmental impact and building up of heavy metals in flora and fauna in aquatic ecosystem has been a cause of great concern in recent years [1]. It causes a decrease in the quality of water, bringing up harmful effects to the flora and fauna and consequently damaging the human health [2]. Nowadays plants that hyperaccumulate metals have tremendous potential for implication in remediation of metals in the environment. The purpose of this study is investigating the accumulation of $\mathrm{Cr}$ in Alternanthera philoxeroides using the SIMS microscopy that permit a precise localization of metal in the cells.

SIMS images showed depositions in stem and root tissues of A. philoxeroides. Cr was deposited mainly in cell wall and vacuole of stem parenchyma (fig 1A,B) and in vessel element of stem xylem (fig. $1 \mathrm{C}, \mathrm{D}$ ). The results indicate that $\mathrm{Cr}$ is strongly adsorbed to the cell walls of the roots and that translocation to the aerial parts is negligible [3]. Fig. $1 \mathrm{E}$ and showed that $\mathrm{Cr}$ can be chelated with organic acids within the vacuoles or small cell vesicles, which are responsible for the detoxification and tolerance to metal stress [4]. A. philoxeroides shows promise for the removal and store storage of $\mathrm{Cr}$ from contaminated wastewater.

The ion images demonstrated that $\mathrm{Cr}$ is preferentially accumulated in cell walls and in some vacuoles of cortical roots cells. The number of $\mathrm{Cr}$ deposits are higher in cortical parenchyma, particularly in vacuoles and cell walls, compared to stellar tissue. This research was supported by CNPq. The aid of Dr. Levi-Setti and Dr Gavrilov of Chicago University is gratefully acknowledged [5].

\section{References}

[1] G. Blázquez, F. Hernáinz, et al. Process Biochen. 40 (2005) 2649.

[2] Panda, S.K., Choudhury, S. Braz. J. Plant Physiol. 17 (2005) 95.

[3] Pulford, I.D., Watson, C. Plant Soil 249 (2003)139.

[4] Srivastava, S., Prakash, S., Srivastava, M.M., Biometals 12 (1999) 201.

[5] The authors wish to thanks Dr Ricardo Levi- Setti , Konstantin Gavrilov (Enrico Fermi Institute, University of Chicago) for their kind assistance with ICP-MS and ion microscopy imaging. This research was supported by $\mathrm{CNPq}$ (Conselho Nacional de Desenvolvimento Científico e Tecnológico, Brazil). 

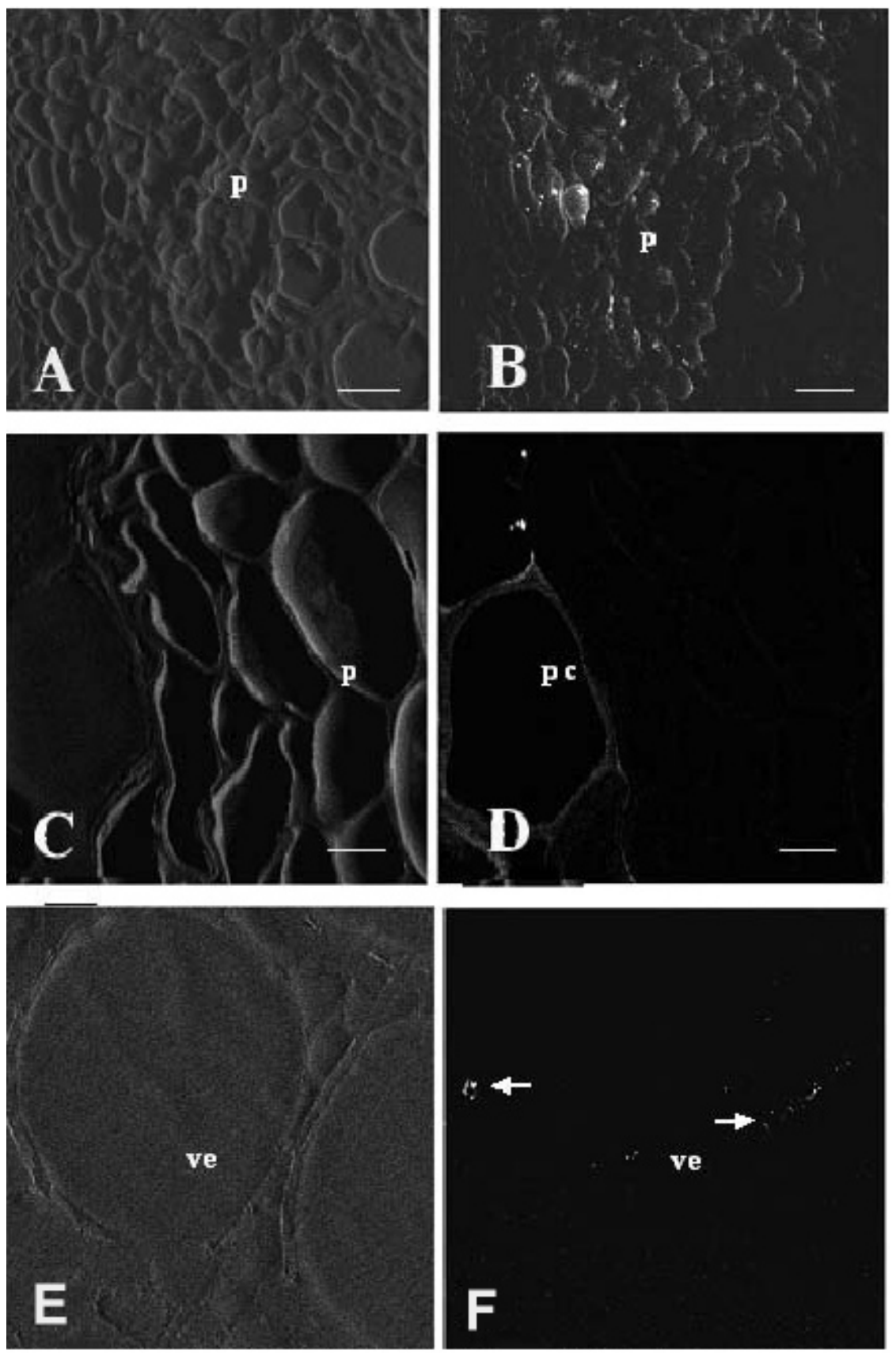

FIG. 1. SIMS images of stem and root tissue of Alternanthera philoxeroides following treatment of plants with $50 \mathrm{mg} \mathrm{L-1}$ Cr. A) global topography of stem parenchyma (p); B) $\mathrm{Cr}_{+3}$ deposits in cell wall and vacuole of stem parenchyma (p) at a depth of $20 \mathrm{~nm} ; \mathbf{C})$ global image of the vessel element (ve) and parenchyma (p) of stem xylem; D) $\mathrm{Cr}+3$ deposits in cell wall of the vessel element of stem at a depth of $20 \mathrm{~nm}$; E) global image of vessel element (ve) of root xylem; F) $\mathrm{Cr}+3$ deposits (arrowed) in the vessel element (ve) of root xylem at a depth of $20 \mathrm{~nm}$. 